el arca

\title{
La eterna pelea por SABER MIRAR
}

Por Facundo Ponce de León
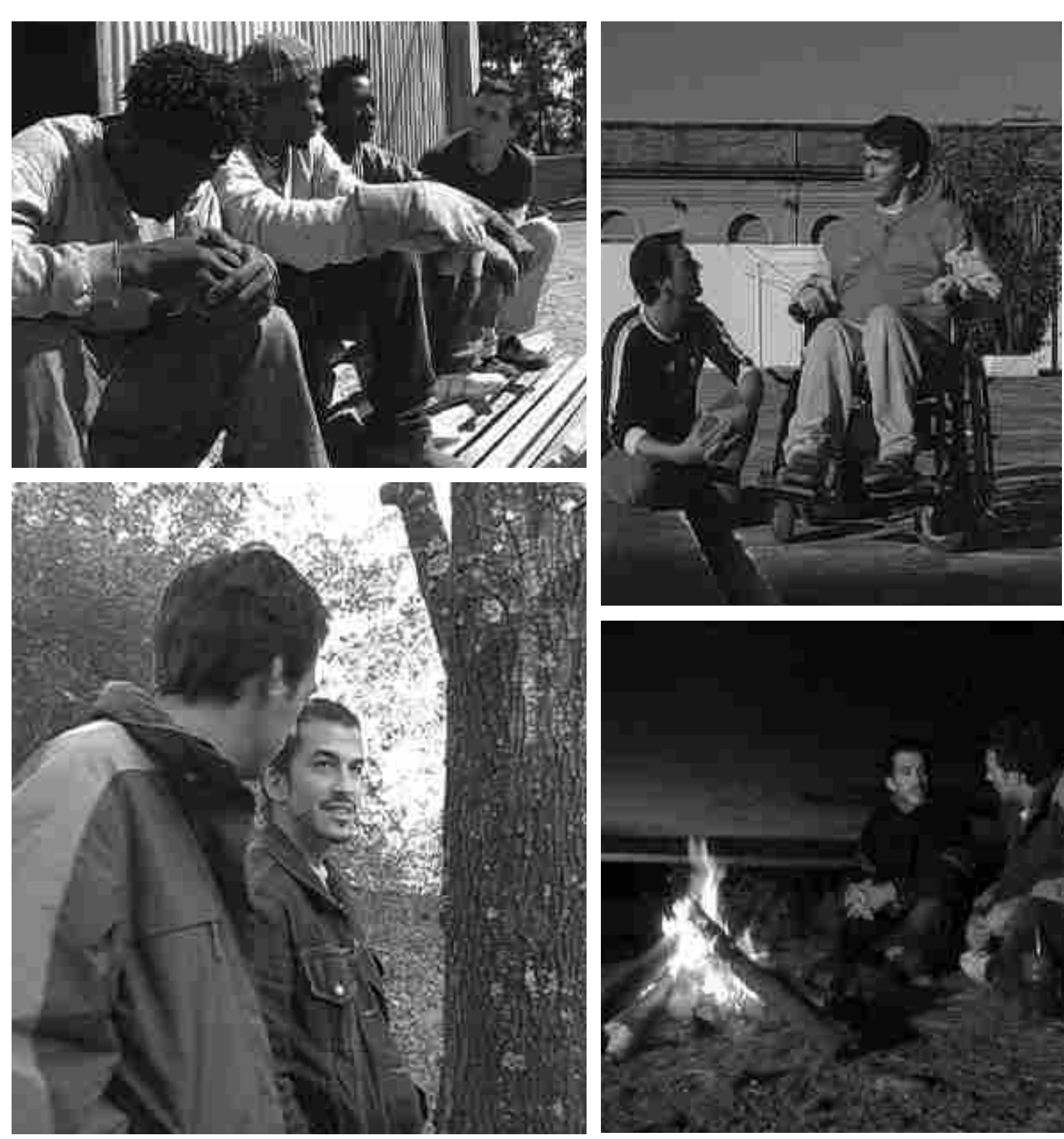
grama Vidas, de la productora Contenidos TV y emitido por el canal 12 en Uruguay durante 2004, 2005, 2006. ${ }^{1}$ El programa consta de un reportaje televisivo a una persona anónima. Como se ex presa en la propia presentación del proyecto televisivo: "Vidas es un impulso. Una necesidad de contar historias que nos dejen algo y nos muestren que a veces las distancias no son tales. Gente común y no tanto, que vive y sobrevive en el Uruguay de hoy, con sus luces y sus sombras. Cada programa busca acercarnos a una vida que en principio sentimos lejos. A través del diálogo, encontramos puentes y fronteras, sin ser efectistas ni buscar el golpe bajo. Creemos en esta manera de contar las historias, dan do una mirada más profunda sobre cada uno de los protagonistas".

El análisis que aquí se presenta revelerá que hay el ementos que hacen de Vidas un caso concreto de la actualidad televisiva pero, al mismo tiempo, hay características que lo alejan de todo encasillamiento actual, básicamente por su explícito proyecto antiespectacular que intenta recuperar la categoría de realidad, deformada por completo en la televisión actual.

Todo es espectáculo. En la década del setenta, a pocos años de que la televisión se masificara, Guy Debord publica La sociedad del espectáculo. Allí diagnostica que la televisión es la irrupción de la irrealidad como modo de vida. Lo que produce la alienación de los humanos en 1967 ya no es la manera de trabajar, como creía Carl Marx, sino que es la espectacularización en la representación de la realidad. La imagen espectacular es el nuevo opio de los pueblos y es un opio invisible, donde nadie se da cuenta que lo aspira y así se transporta a un mundo que no existe, a un "ver por ver", a un simulacro de realidad que, como luego explicó J ean Baudrillard, es el producto de fundir la realidad en la ficción. Esta fusión, lejos de producirse en un ámbito específico, es transversal a todas las esferas de la vida: economía, política, sociedad, cultura, relaciones personales, laborales... Todo se realiza y se interpreta en clave de espectáculo, o lo que es lo mismo para Debord, en la lógica del mostrar por el mero hecho de mostrar. Lo que ven los ojos es un completo engaño. En el espectáculo, imagen de la economía reinante, el fin no existe, el desarrollo lo es todo. El espectáculo no quiere llegar nada más que a sí mismo (...) no es un suplemento al mundo real, su decoración añadida. Es el corazón del irrealismo de la sociedad real. ${ }^{2}$

El análisis de Debord, a pesar de su pesimismo y su apego a la visión marxista de la sociedad, no deja de acertar en el hecho de que la sociedad occidental crece sostenidamente en consumo y espectáculo. El sistema capitalista nacido de la ética puritana como mostró Max Weber, hoy paradójicamente nos pide que seamos sujetos de placeres constantes para que el mercado funcione. El sistema es consumo desenfrenado y éste se lee y se produce en clave espectacular. Dentro de esta lógica se encuentra todo fenómeno televisivo y Vidas no es la excepción. En este sentido, el programa es un objeto de consumo espectacular. No obstante, podemos encontrar en la propuesta televisiva elementos opuestos a los que definen la televisión actual. Un esbozo de estos elementos ocupará las páginas siguientes.

Telerrealidad. Gerard Imbert define la telerrealidad como "voyeurismo mediático que sustituye a menudo el discurso del saber, una lógica del ver por ver, que la televisión ha llevado hasta su extremo y que la telerrealidad ha consagrado, con su deriva hacia una visibilización a ultranza de la intimidad". ${ }^{3}$ Por detrás de esta idea, está la noción de simulacro de Baudrillard que apela a una noción que subsume realidad y ficción en una tercera categoría dinámica. Vidas busca, dentro de la propia lógica del simulacro, salir de ella, desvelar una realidad que se impone más allá de toda televización. La paradoja de hacer esto desde un programa televisivo es una prueba de pelea dentro del sistema, o dicho de otro modo no menos paradójico, de espectáculo antiespectacular. Un ejemplo se puede apreciar en el programa de Martín, un bombero que tuvo que ir a cubrir un accidente fatal en que una madre había muerto junto a sus dos hijos pequeños aplastados por un camión. Al llegar al lugar, se informa que en breve se procedería a quitar los cuerpos que estaban destrozados dentro de un vehículo. En la lógica espectacular, hiperreal, mostrar ese trabajo lo más cerca posible sería sinónimo de audiencia ávida de monstruosidad. Para colmo, llovía sin parar. Luego de una nota a Martín en la que ex plica que lo que va a tener que hacer es de las cosas más difíciles de su profesión (no retira un cuerpo sino 
pedazos de cuerpos), el programa va a una pausa con una imagen de la lluvia a través de un vidrio. Nada se mostró a pesar de que el suceso parecía hecho a medida dela telerrealidad. ${ }^{4}$

Mostrar lo cotidiano vs. contar lo cotidiano. Un segundo elemento paradójico de Vidas es el hecho de querer representar una realidad cuando en realidad se la está mostrando. Régis Debray definió la sociedad el espectáculo como "la democracia del momento: vivir en conexión directa con un universo de acceso directo, 'todo y en el acto', amplio autoservicio sin ceremonia". 5 i seguimos este argumento concluimos que se diluye la representación y nos alojamos en el mero mostrar, donde no hay distancia porque todo es ver inmediatamente. Los teóricos Ilaman a este proceso la hiperrealidad, lo que hace y perpetúa la televisión diariamente con la irrupción en la pantalla de la cotidianeidad. Ésta fue entendida, tanto en los realities como en documentales, como una eliminación dela distancia, como una muerte del relato y de la reflexividad que apareja la distancia del narrar.

Inserta en la cotidianeidad, la propuesta de Vidas busca romper la autoreferencialidad de la televisión actual e introducir elementos reflexivos. Quizás un ejemplo en esta línea sea el suceso vivido con Walter, un policía de patrulla que tuvo que asistir a una Ilamada de un presunto suicidio. ${ }^{6}$ Al llegar al lugar no estaba claro si se trataba de una autoeliminación o un asesinato. Se detuvo a toda la familia y la situación se tornó tensa y caótica. Gritos, insultos, y el cuerpo muerto con un revolver al costado. Luego de estar en la escena y mostrarla, se pasa a una nota reflexiva de la situación, donde Walter y otro policía explican lo que se estaba mostrando y la mecánica legal y social del trabajo en ese tipo de situaciones. La distancia frente al suceso era una forma representarlo, de darle sentido. En otras palabras, lo que podría haber sido una escenificación espectacular de lo privado (el policía dentro del hogar) se enfoca como experiencia humana en busca de sentido (la de los policías en este caso) y no como una cuestión de mero mostrar, que es como plantean los realities la interacción cotidiana.

Un aspecto no menor es que la nota con los policías fue en medio de la noche, acompañada de muchos silencios tanto en preguntas como en respuestas. El silencio siempre es una forma de distanciamiento, pero lo es mucho más en el contexto actual de la televisión, definida por J esús González Requena como "negadora del silencio". "Digámoslo de una vez: en el espacio fracturado, esquizoide, de la postmodernidad, los 'medios de comunicación de masas' bajo la cobertura de su simulacro de comunicación, y bajo el incentivo seductor del espectáculo que construyen, terminan por convertirse en generadores de un ruido incesante con el que el sujeto pretende tapar la emergencia de lo real (...) Lo que se olvida es, después de todo, algo tan sencillo como esto: que para que la comunicación pueda conservar su digno nombre lo importante es tener algo (necesario) que decir y decirlo, sólo, cuando es necesario. 0 , en otros términos, que sólo el silencio dota de sentido y espesor a la palabra".

La vida de Alejandro, hijo de padre y madre desaparecidos durante la dictadura militar en Uruguay (1973-1984), emitido el 24 de julio de 2006, puede ser interpretado enteramente en esta clave de un programa que busca darle a la televisión un poco de silencio. Durante toda la entrevista y sobre todo en el último bloque, un profundo silencio acompaña las reflexiones de Alejandro sobre su vida. Al igual que en el caso de Walter, el objetivo es que lo cotidiano, no por ser mostrado, se convierta en hiperrealidad, en sinsentido. Un último aspecto con respecto a la cuestión del silencio tiene que ver con la musicalización del programa. Desde la canción que funciona como cortina de la presentación (una adaptación del tema Skyway de la banda The Replacement) hasta las canciones que acompañan cada historia que se cuenta, la música busca tener un rol silencioso (lo que no quiere decir neutro) entre el estruendo espectacular. Y esta sería una paradoja más, entre las tantas que estamos viendo: querer introducir el silencio en televisión a través de sonidos y palabras que no griten.

Héroes cotidianos. La cotidianeidad Ilevada a la televisión aparejó dos fenómenos concatenados: la importancia de la oralidad ${ }^{8}$ y el ciudadano común elevado a la categoría de famoso, de divo. Vidas toma sólo el primero de estos elementos y se distancia del segundo. El programa, amen de la acción visual, está basado en la oralidad, en la conversación que busca reflexionar sobre la acción que se está viviendo. No
4::

Programa emitido el martes 26 de abril de 2005 . 5:: Imbert, op. cit., pág 72 . 6:: Emitido el lunes 17 de julio de 2006. 7::

J esús González Requena, El discurso televisivo: espectáculo de la postmodernidad, Cátedra, Madrid, 1988, página 159-160 8::

Se habla de oralidad en el sentido de una televisión que constantemente habla de sí misma, que tiene programas que se autorrefieren simplemente hablando (sin acción visual) unos de otros. Un ejemplo típico son los programas de mesas redondas donde se "analiza" (sólo se habla) del

comportamiento de los concursantes de un reality. 
9::

Imbert, op. cit., pág 77 .

10::

Ibídem.

11::

Salvador Alsius, Catorce dudas sobre el periodismo en televisión (prólogo de Victoria Camps), CIMS, Barcelona, 1997, pág. 71.

Ignacio Ramonet, charla de periodistas de Radio Nederland con Ignacio Ramonet sobre los mass media en "Seminario de capacitación profesional" ofrecido por Ignacio Ramonet al personal del departamento latinoamericano de Radio Nederland", publicado en 2003 en <http://www.rnw.nl/ informarn/html/esp sociedad e informacion_ram.html>

El mismo argumento puede verse en Pierre Bourdieu, Sobre la televisión, Angrama,

Barcelona, 1997. En especial el apéndice sobre periodismo y política.

Una hipótesis de explicación es que Vidas se traza como objetivo el carácter representacional de la vida que se está contando, su no disolución en el mero mostrar televisivo cotidiano. En la visión reality show del ciudadano común se desemboca en la "crisis de la verdad, al fin y al cabo, porque lo que importa es menos lo que se dice sobre la realidad (en forma de representación, reflexión) que la realidad misma, lo que transcurre en tiempo real; con esto, se tambalea el referente y la relación de veridicción con él". ${ }^{10}$ Vidas quiere evitar este peligro y recuperar el 'sentido' en la historia y no la divinización del instante a pesar de que durante todo el programa no se mire a la cámara y parezca que sólo se está mostrando.

Tiempo. Más arriba mencionamos el tema de la sacralización del instante que realiza la televisión actual. Se abre con esto la dimensión de la temporalidad, elemento fundamental que sólo rozaremos aquí. Una manera posible de leer la historia de la televisión es cómo entiende la temporalidad, es decir, cómo significa el tiempo del espectador y cómo significa el tempo del propio medio.

En esta línea, por ejemplo, Salvador Alsius, se pregunta si es posible explicar el mundo en treinta minutos, cuando a un medio de comunicación llegan unas 1.000 noticias diarias y en un noticiero entran no más de 20. "La parquedad del tiempo dedicado a cada tema impide casi siempre exponer todos sus matices". ${ }^{11}$ ¿Qué es entonces lo que se hace con el tiempo en la televisión? ¿Se le da sentido o se lo pervierte? Permítaseme una cita extensa de Ignacio Ramonet sobre el tema de la verdad en los 'mass media' que refiere directamente al problema del tiempo. "¿Qué es la verdad hoy?, ¿quées lo que se impone como verdad? Si todos los medios prensa, televisión, radio dicen que algo es verdad, eso es verdad. Nuestra sociedad, nuestro sistema de filosofía mediática hace que, cuando todos los medios dicen que algo es así, eso se impone como verdad. $Y$, si usted dice lo contrario, aunque tenga la razón, aparecerá como alguien exótico y no creíble, como dice Chomsky. Por ejemplo, si a usted lo invitan a la tel evisión, o a cualquier medio, donde hay que hablar en 30 segundos, con la orden siguiente: "dígamelo todo, pero sea muy breve". ¿Cómo se puede salir de esa apuesta imposible: decirlo todo y ser muy breve? Ustedes saben lo que los griegos Ilaman "la doxa": es la verdad que se acepta colectivamente. (...) si usted dice la doxa, la verdad generalmente admitida, pues lo puede decir en 15 segundos, ni siquiera necesita 30 segundos (...) Si usted dice lo contrario de todo lo que el mundo cree, evidentemente, necesita un poquito más de tiempo para explicar los elementos que constituyen su razonamiento. Pero, los medios no aceptan los razonamientos, sólo aceptan las impresiones...". ${ }^{12}$

La base del razonamiento de Ramonet es que hay cosas que llevan tiempo y a eso se niega la televisión porque significa pervertir el espectáculo, pulmón principal dela actividad. ${ }^{13}$ El el emento clave que busca introducir la propuesta de Vidas es el de darse un tiempo dentro del medio televisivo sin desconocer el timing del propio medio.

Esta idea juega en dos niveles: tiempo para realizar la nota (16 horas) y tiempo de emisión televisiva (una hora con la misma historia, desentrañando la misma información). Este elemento temporal, este "tomarse el tiempo para hacer el programa" y "tomarse un tiempo para verlo", lleva consigo el objetivo ético de creer que no se puede mostrar por mostrar, sino que, dentro de la lógica de la "mostración", hay que narrar una historia, hay quetejer un sentido. 

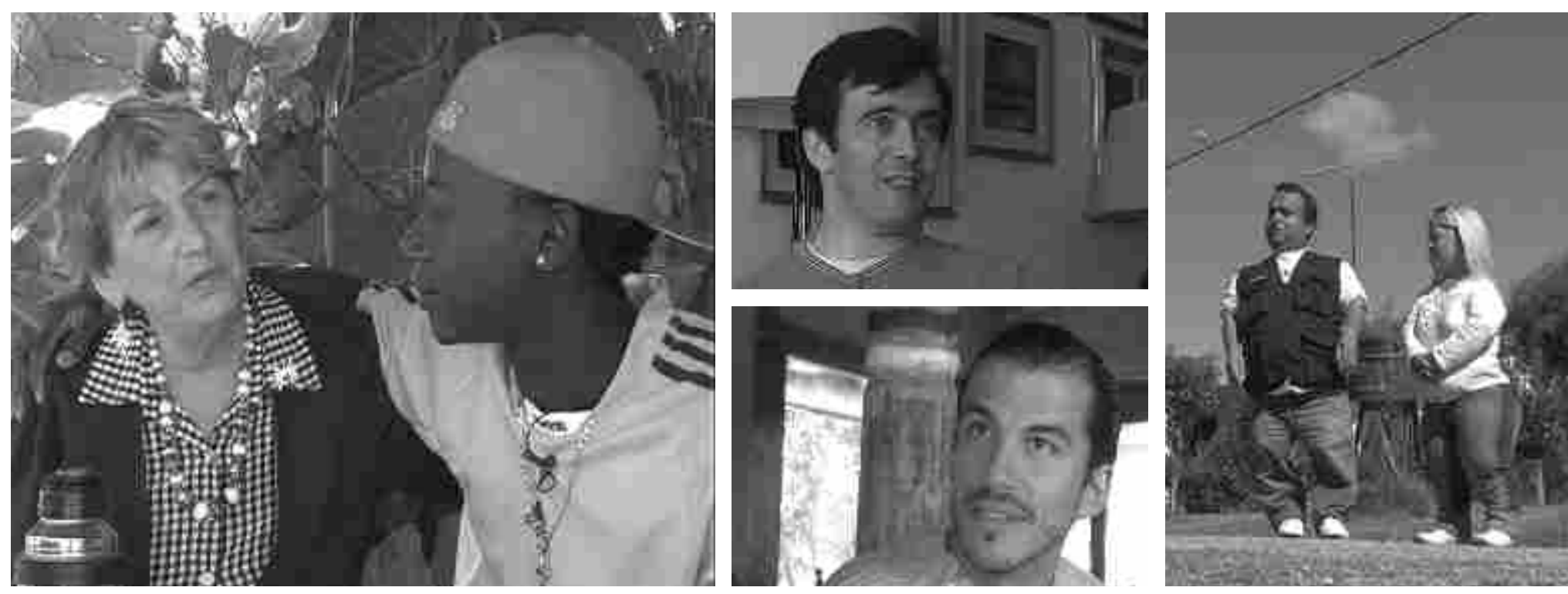

La invisibilidad vs. el mundo. Si seguimos la línea que plantea Umberto Eco en La transparencia perdida, la neotelevisión se caracterizaría por irrumpir en la realidad desde lo redundante, lo autoreferencial y la creación de una realidad sui generis. A su vez este proceso genera la fascinación por lo invisible, por mostrar lo que no se puede ver, "explorando en las superficies, aunque se pretenda bucear en las profundidades del alma humana".14 Aquí también encontramos un juego paradójico en el programa Vidas. Por un lado, siguiendo esta línea teórica, el programa es una exhibición de intimidades, ingresa en lo invisible de las personas, en su habitación, en sus problemas más privados. No obstante, ese ingreso se realiza desde un esquema narrativo, desde un mensaje que se quiere construir-transmitir. Un buen ejemplo de este aspecto puede ser el ingreso en la cama de Marcelo, una hombre cuadriplégico de 30 años que no pude valerse por sí mismo. Para acostarse necesita que sus padres lo coloquen en la cama. Mostrar esa escena íntima, familiar, tiene dos objetivos claros para el propio protagonista, a saber, el amor de sus padres, y el problema del sueño de las personas paralíticas, que deben dormir con un timbre al costado ante la imposibilidad de moverse. ${ }^{15}$

La acción, aunque íntima, se registró con recato, con distancia narrativa evitando lo que denuncia Imbert como "pulsión escópica que nos lleva a adentrarnos cada vez mas en lo invisible, a saltarnos todas las reglas sociales (el recato, el pudor)". ${ }^{16}$

A dentrarse en lo invisible pero reconociéndolo como invisible es, en definitiva, ubicarlo como referente, colocarlo en el orden de la representación y no en el de la duplicación de lo real. Con ello, se busca invertir la falsa cercanía de la neotelevisión (basada en la atemporalidad y la transparencia) por una cercanía de otro orden, "más real" si se quiere utilizar la expresión del sentido común o más pasiva si se refiere al rol del televidente. La cercanía que propone Vidas no implica a un espectador cercano a la televisión, que forme parte de ella votando, enviando mensajes de texto, creando con sus fotos o videos secciones del programa, en definitiva, siendo coautor del espectáculo. Por el contrario, el propósito de cercanía que se le propone es que conozca una historia, no que intervenga en ella. En este sentido, Vidas estaría más cerca de lo que Eco llama paleotelevisión, aquella que busca hablar de un mundo exterior a la propia pantalla y que hoy ya casi no existe.

Revivir el referente podría ser el lema de la propuesta de Vidas. La apuesta de la televisión actual es que todo lo que pasa es lo que se ve en ella. Vidas, paradójicamente, busca mostrar desde la televisión que hay que aprender a mirar por fuera de ella misma. Que hay mundo. Y es ahí donde debemos poner los ojos.:-
14:: Gérard Imbert, "Nuevas formas televisivas: el transformismo televisivo o la crisis de lo real (de lo informe a lo deforme)", en Revista Télos, Núm. 62, eneromarzo de 2005, pág 3 15::

Programa emitido el 10 de julio de 2006 .

16::

Imbert, op. cit., pág 4 